\title{
Investigation of the Elastic Modulus of SSC Coils
}

\author{
F. Markley, J. Kerby, B. Sizemore, C. Khoun, and T. King \\ Fermi National Accelerator Laboratory \\ P.O. Box 500, Batavia, Illinois 60510
}

\begin{abstract}
March 1991
* Presented at the Third Annual International Industrial Symposium on the Super Collider [IISSC], Atlanta, Georgia, March 13-15, 1991.
\end{abstract}




\section{Disclaimer}

This report was prepared as an account of work sponsored by an agency of the United States Government. Neither the United States Government nor any agency thereof, nor any of their employees, makes any warranty, express or implied, or assumes any legal liability or responsibility for the accuracy, completeness, or usefullness of any information, apparatus, product, or process disclosed, or represents that its use would not infringe privately owned rights. Reference herein to any specific commercial product, process, or service by trade name, trademark, manufacturer, or otherwise, does not necessarily constitute or imply its endorsement, recommendation, or favoring by the United States Government or any agency thereof. The views and opinions of authors expressed herein do not necessarily state or reflect those of the United States Government or any agency thereof. 
INVESTIGATION OF THE ELASTIC MODULUS OF SSC COILS.

\author{
F. Markley, J. Kerby, B. Sizemore, C. Khoun, and T. King
}

Fermilab National Accelerator Laboratory

Box 500

Batavia, IL 60510

\begin{abstract}
The Materials Development Laboratory at Fermilab has been conducting experiments on the mechanical properties of superconducting coils. Two of these measurements were designed to measure the elastic modulus of actual SSC coils in an effort to increase the precision of previously reported data. The first experiment utilizes a fixture redesigned for increased stiffness, in an attempt to reduce uncertainty in the data. As in the previous fixture of this type, the inner coil radius has been left unconstrained. The second fixture constrains the coil on all sides, allowing for the determination of the radial and azimuthal components of the cured coil modulus.
\end{abstract}

A finite element model of the first test arrangement was also created to predict the compliance of the fixture, and compare numerical predictions with the experimental data. The results from this fixture suggest that the coil modulus is higher than previously reported, at $1.43 \pm 0.03 \times 10^{10} \mathrm{~Pa}\left(2.08 \pm .05 \times 10^{6} \mathrm{psi}\right)$. The main difference between the two experiments were the compliance of the fixture, which was found to have been seriously underestimated in last years tests. Results from the second fixture suggest a coil modulus of $8.48 \pm 0.82 \times 10^{9} \mathrm{~Pa}\left(1.23 \pm 0.12 \times 10^{6} \mathrm{psi}\right)$ for the azimuthal modulus, and between $8.96 \pm 0.822$ $\times 10^{9} \mathrm{~Pa}\left(1.3 \pm 0.12 \times 10^{6} \mathrm{psi}\right)$ at lower loads and $1.12 \pm 0.24 \times 10^{10} \mathrm{~Pa}\left(1.63 \pm 0.35 \times 10^{6} \mathrm{psi}\right)$ at higher loads in the radial direction. For a constrained coil, little difference is noted between the radial and azimuthal moduli of the coil.

\title{
INTRODUCTION
}

The mechanical properties of superconducting coils have been under investigation for a considerable time. ${ }^{1,2}$ With the use of higher and higher central fields in magnets, knowledge of these properties is becoming more critical as coils are compressively loaded, in increasingly complex ways, to reduce the likelihood of quenches due to mechanical motion of the coil during excitation. The Materials Development Laboratory at Fermilab has been conducting an ongoing investigation of these properties, including two experiments designed to measure the elastic modulus of cured coils.

The first experiment is an improved version of that reported last year, ${ }^{2}$ where the coil inner radius is left unconstrained. By reducing the fixture compliance, and better understanding the corrections to the data, a more accurate result has been obtained. This redesigned fixture consists of a single, precision machined block in which the cavity 
exactly matches the shape of the cured coil. Furthermore, by reducing the number of pieces in the fixture, the uncertainties associated with mating of gaps between the pieces is removed. Finally, the load mechanism has been redesigned to apply a more uniform load directly to the coil "midplane", rather than through the pole support piece of the fixture to the coil (figure 1). This design minimizes any bending of the load assembly which could affect the results. The coil midplane deflection is measured by an LVDT, which is located on the axis of the applied load. A small ANSYS model has also been created (figure 2), which has been used to predict and check the compliance of the fixture.

The second experiment allows for the determination of the radial and azimuthal components of a constrained coil. Either through the use of a lever bar, or reactions against the end supports as shown later, an azimuthal or radial load can be applied to the coil sample. By necessity, this fixture requires the use of a greater number of pieces, and is not as simple as the first. Translational displacement of the load lever or of the load assembly is recorded for the azimuthal or radial tests, respectively.

\section{RESULTS}

The objective of the first experiment, shown in figure 1, was to increase the precision of the elastic modulus measurement. For this, three sections of cured $40 \mathrm{~mm}$ SSC outer coil were obtained. The improvements to the fixturing meant that the pole face and outer arc of the coil mated exactly with that of the fixture cavity. The data were obtained by placing the section in the fixture, and gradually increasing the load applied to the coil by the Instron load cell. After reaching a load of about $5000 \mathrm{~kg}(11026 \mathrm{lb})$, the load was then gradually decreased to 0 . Before taking another data point with the same sample, the sample was removed from the fixture, and replaced. This ensured that the data points are independent of one another. Although the use of pieces of the same coil, as in these tests, is not ideal, we are limited by the availability of the cable and cured coil sections.

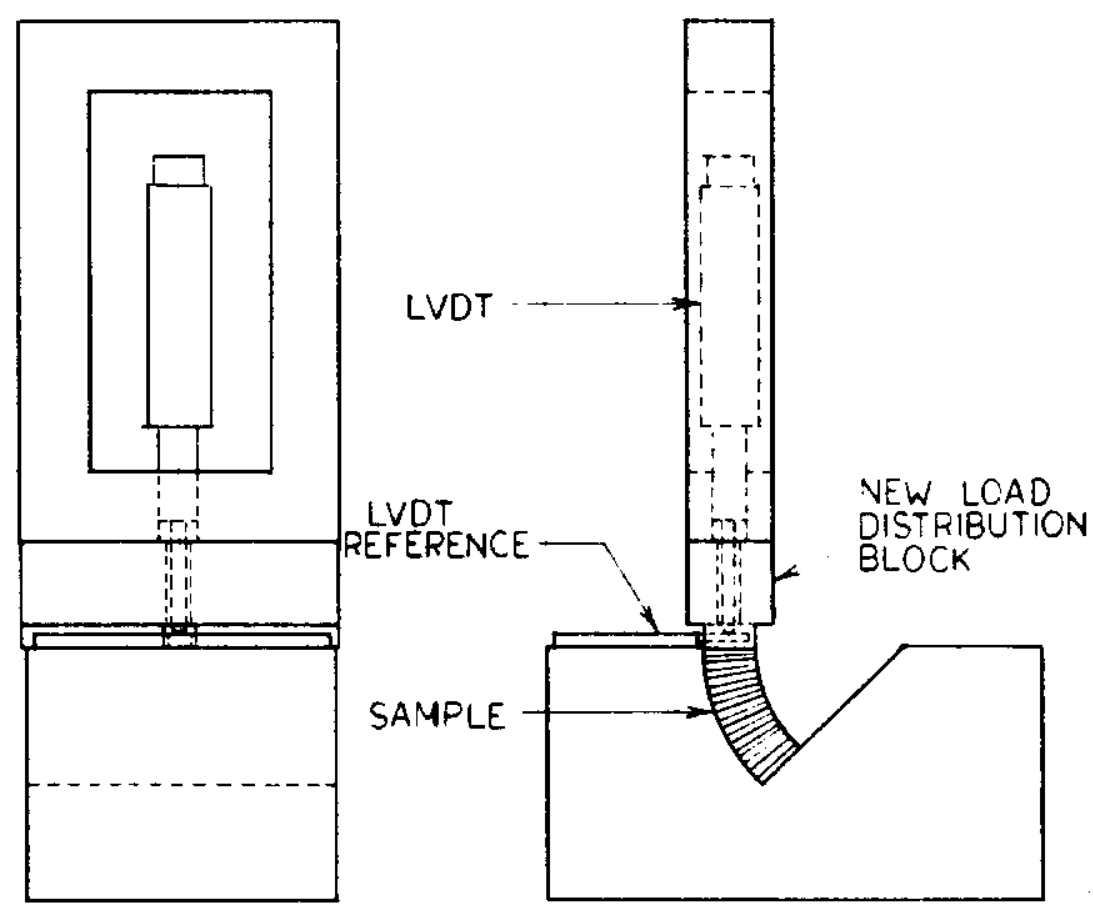

Figure 1. Fixture for Azimuthal Modulus Tests 


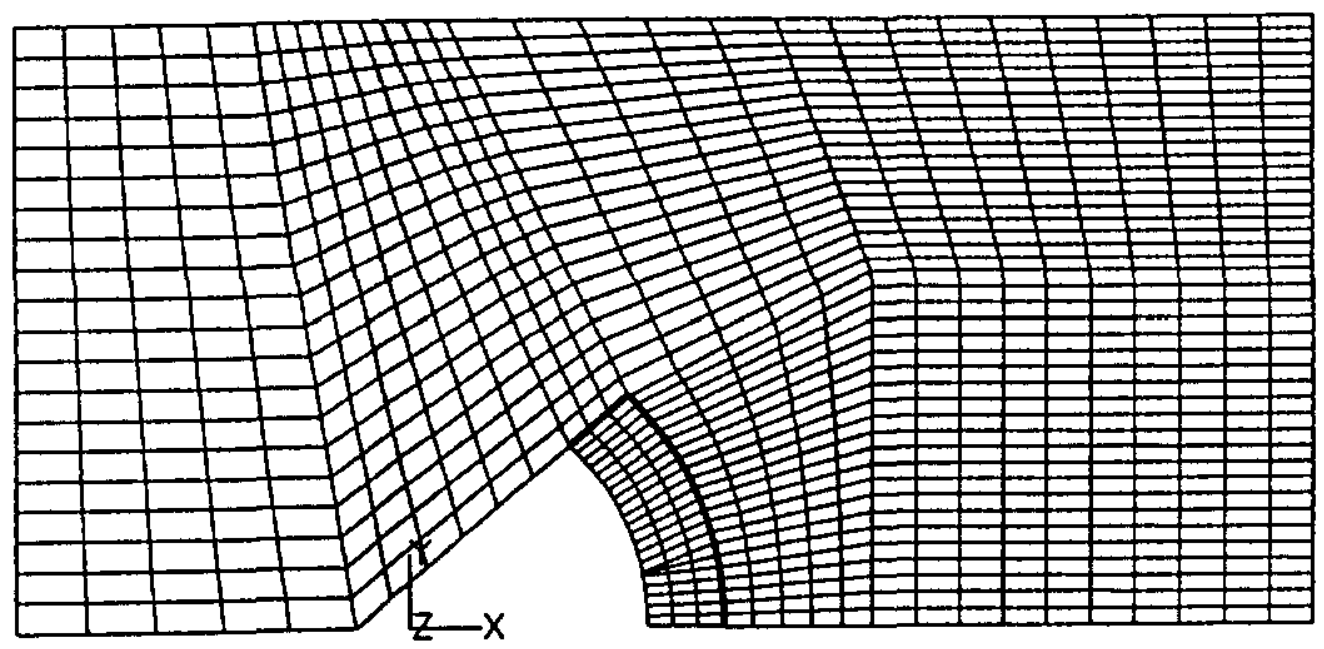

Figure 2. ANSYS Mesh Azimuthal Load Fixture

The fixture compliance was determined by loading an aluminum "coil", of known modulus, and recording the measured deflection. By subtracting the calculated deflection of the sample, the fixture load assembly compliance as a function of load was determined. These results are presented in Table 1 .

The three coil samples were then loaded, five times each, and the deflections recorded. A typical plot of load versus deflection for one of these coils is shown in figure 3. The hysteresis effects are typically attributed to friction between the coil and the fixture cavity, so that the loading curve lies to the left of the unloading curve. The slope of the curves is also markedly different, so it should be noted that we used the linear portion of the increasing load curve.

A table showing the measured deflections at peak load, corrected deflection and deduced linear elastic modulus is shown in Table 2. Although a limited statistical sample, the data are grouped well, giving a mean elastic modulus of $1.43 \pm 0.03 \times 10^{10} \mathrm{~Pa}$ $\left(2.08 \pm 0.05 \times 10^{6} \mathrm{psi}\right)$ at an average coil stress of $6.56 \times 10^{7} \mathrm{~Pa}(9520 \mathrm{psi})$.

Table 1. Experimental Calculation of Fixture Assembly compliance (7 trials)

Measured Deflection w/ Aluminum Bar Calculated Aluminum Bar Deflection Calculated Fixture Ass'y Compliance

$$
\begin{array}{lll}
0.034 \pm .001 \mathrm{~mm} & (1.32 \pm .02 \text { mils }) \\
0.027 \mathrm{~mm} & (1.07 & \text { mils }) \\
0.006 \mathrm{~mm} & (0.25 & \text { mils })
\end{array}
$$




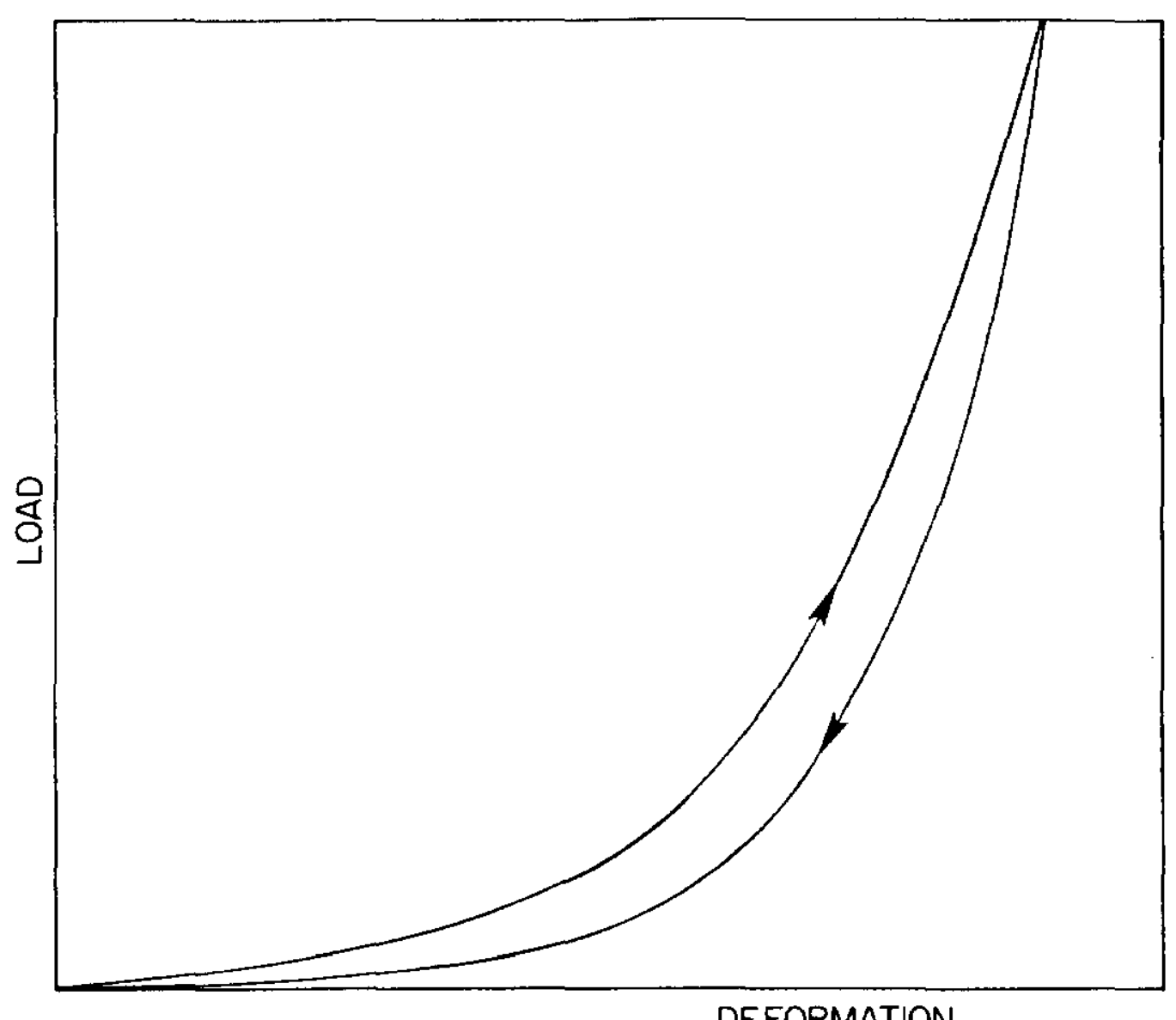

Figure 3. Typical load-deformation curve for coil in fixture \#1

The ANSYS model of the fixture was used to confirm the fixture compliance. The two dimensional model uses linear quadrilateral area elements, with frictionless gaps used for the coil section to fixture interface. The load was applied as a pressure on the midplane of the coil only. Three load cases were tried, in which the nodes of the coil section midplane were constrained in varying fashions. Since the exact relationship between the load head and the sample is unknown, these models attempt to bound the problem since the load head is not included in the model. The load cases are then: 1) a pressure load, with the with no additional restraints on the nodes (a freely conforming load head); 2 ) the pressure load with the nodes of the midplane constrained so that motion in the vertical direction is equal (a perfectly rigid load head); and 3 ) the pressure load with the nodes of the midplane constrained to move only in the $Y$ direction, but not necessarily equal to one another. The average deflection of the midplane of the aluminum sample for each of these load cases is presented in Table 3 , as well as the fixture compliance.

Table 2. Measured Coil Deflection and Calculated Modulus

$\begin{array}{cccc}\text { Sample } & \text { Measured Deflection } & \text { Corrected Deflection } & \text { Calculated Modulus } \\ \text { G } & 0.135 \pm 0.005 \mathrm{~mm} & 0.129 \mathrm{~mm} & 1.49 \pm 0.07 \times 10^{10} \mathrm{~Pa} \\ & (5.33 \pm 0.21 \mathrm{mils}) & (5.08 \mathrm{mils}) & \left(2.10 \pm 0.10 \times 10^{6} \mathrm{psi}\right) \\ \mathrm{R} & 0.141 \pm 0.002 \mathrm{~mm} & 0.134 \mathrm{~mm} & 1.40 \pm 0.02 \times 10^{10} \mathrm{~Pa} \\ & (5.54 \pm 0.09 \mathrm{mils}) & (5.29 \mathrm{mils}) & \left(2.02 \pm 0.03 \times 10^{6} \mathrm{psi}\right) \\ \mathrm{E} & 0.136 \pm 0.001 \mathrm{~mm} & 0.129 \mathrm{~mm} & 1.49 \pm 0.01 \times 10^{10} \mathrm{~Pa} \\ & (5.34 \pm 0.05 \mathrm{mils}) & (5.09 \mathrm{mils}) & \left(2.10 \pm 0.02 \times 10^{6} \mathrm{psi}\right)\end{array}$


Table 3. Calculated Aluminum Insert Deflection and Fixture Compliance

$\begin{array}{lccc} & \text { Load Case 1 } & \text { Load Case 2 } & \text { Load Case 3 } \\ \text { Aluminum } & -0.00100^{\prime \prime} & -0.00098^{*} & -0.00101^{\prime \prime} \\ \text { Fixture } & -0.00017^{\prime \prime} & -0.00020^{\prime \prime} & -0.00018^{\prime \prime}\end{array}$

The average deflection of the aluminum fixture is seen to be a weak function of the load constraint, although the local variation of deflection under load is greater for the first load case than the second or third. Good agreement, within $10 \%$, is achieved with the linear bar approximation used for the aluminum insert in the reduction of the experimental results, although the difference suggests that the linear approximation does not account for the distribution of the load through the aluminum insert and the support given by the fixture.

The deflection of the fixture itself agrees to within microns with that measured experimentally, and suggests that the fixture compliance has been reduced by an order of magnitude from the previous test fixture. The deflection of the fixture should now account for less than $5 \%$ of the uncertainty in the measurement of the coil samples.

The second test fixture, which constrains the coil on all sides, was used to measure both the azimuthal modulus and the radial modulus. Figure 4 shows a cross section through the apparatus showing how the azimuthal force was applied through the central bar, while figure 5 is an external view of the apparatus showing how the linear motion of the Instron testing machine was converted to a torque in the central bar which applied the azimuthal force. To determine the compliance of this fixture, a stainless steel block was substituted for the coil and a force deflection curve measured. The calculated deflection of the steel block alone was then subtracted, giving a force deflection curve for the fixture alone (figure 6, curve 1 ). To verify this value, an aluminum block was also placed in the fixture, and a force-deflection curve measured. After subtracting the fixture deflection curve, the resulting deflection curve for the aluminum sample is shown as curve 2 of figure 6. The curves have been normalized along the horizontal axis to have equal deflections at $4535 \mathrm{~kg}(10000 \mathrm{lb})$ load. From the slope of this curve, along with the measured angular displacements of the load arms shown in figure 5 , and the area of the sample, a modulus can be calculated. The result for the aluminum sample was $6.69 \times 10^{10} \mathrm{~Pa}\left(9.7 \times 10^{6} \mathrm{psi}\right)$, which is in very good agreement with the expected $6.90 \times 10^{10} \mathrm{~Pa}\left(10 \times 10^{6} \mathrm{psi}\right)$.

Four sections of coil previously measured in fixture 1 were then measured in this fixture. The corrected force deflection curves for each of these samples are shown as curves 3 through 6 in figure 6. The slopes of these curves convert to moduli of $8.27 \times 10^{9} \mathrm{~Pa}$ $\left(1.2 \times 10^{6} \mathrm{psi}\right)$ for section $\mathrm{D}, 7.58 \times 10^{9} \mathrm{~Pa}\left(1.1 \times 10^{6} \mathrm{psi}\right)$ for section $\mathrm{E}, 8.96 \times 10^{9} \mathrm{~Pa}\left(1.3 \times 10^{6} \mathrm{psi}\right)$ for section $G$, and $8.96 \times 10^{9} \mathrm{~Pa}\left(1.310^{6} \mathrm{psi}\right)$ for section $\mathrm{R}$, giving an average of $8.48 \pm 0.21$ $\times 10^{9} \mathrm{~Pa}\left(1.23 \pm 0.03 \times 10^{6} \mathrm{psi}\right)$, which is somewhat smaller than that found for the azimuthal modulus in fixture 1. It should be noted that when repetitive tests were run in this fixture, each successive measurement would yield a load deflection curve with a steeper slope. This is apparently due to a "seating in" of less than perfectly mated parts, and after several repetitions this would stop. As a result, we have only used the load deflection curves obtained after 10 successive loading and unloading cycles.

Figure 7 shows how the test apparatus was arranged for the radial tests. The force on the central bar was applied through the two end supports shown in figure 5 . The coil sections are, of course, in the central section, and spacers are used to constrain the coil azimuthally. The load deflection curves from this test are shown in figure 8 . As before, curve 1 is the fixture deflection, curve 2 the corrected aluminum block deflection, and curves 3 through 6 the corrected deflections of the four coil samples. Once again, all curves have been normalized along the horizontal axis to give the same deflections at $4535 \mathrm{~kg}$ $(10000 \mathrm{lb})$ load. Unfortunately, after transforming the data to moduli, the aluminum curve gives a value of only $2.34 \times 10^{10} \mathrm{~Pa}\left(3.410^{6} \mathrm{psi}\right)$. If we accept this as error due to the subtraction of the large fixture deformation from a similar magnitude measurement, and calculate the coil moduli, the result is $8.96 \times 10^{9} \mathrm{~Pa}\left(1.3 \times 10^{6} \mathrm{psi}\right)$ for section $\mathrm{D}, 9.65 \times 10^{9} \mathrm{~Pa}$

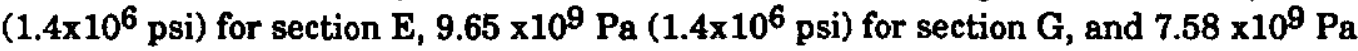




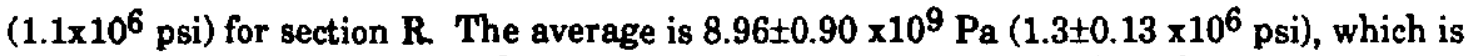
very close to the azimuthal values. However, previous experience has shown the aluminum blocks to provide better compliance data, possibly because the aluminum itself deforms easier than steel to account for any geometric mismatches between the block and the fixture. If the aluminum block had been used to determine the fixture compliance, as was done in the fixture 1 tests, the calculated sample deflections are shifted by the difference between the compliance when calculated with the aluminum and steel blocks. The calculated moduli of the samples will then increase by a small amount which we have not yet calculated.

For the radial tests, the data were taken at a much smaller stress than in the azimuthal case, since the same maximum load was used but across a much larger area. Since all data for SSC coils so far has shown modulus increasing with load, a maximum load of $13603 \mathrm{~kg}(30000 \mathrm{lb})$ was applied to see if the new results would agree better with those from fixture 1. This was not very successful. After again using the steel block to determine the fixture deformation, the aluminum modulus was determined to be only 2.69 $\times 10^{10} \mathrm{~Pa}\left(3.9 \times 10^{6} \mathrm{psi}\right)$, and the moduli of the coil sections $\mathrm{D}, \mathrm{G}, \mathrm{E}$, and $\mathrm{R}$ of $8.27 \times 10^{9} \mathrm{~Pa}$

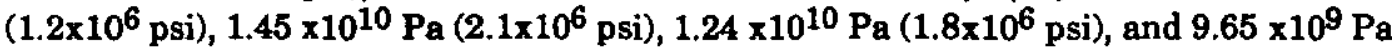
(1.4x $\left.10^{6} \mathrm{psi}\right)$, for an average of $1.12 \pm 0.24 \times 10^{10} \mathrm{~Pa}\left(1.63 \times 10^{6} \pm 0.35 \times 10^{6} \mathrm{psi}\right)$.

The best we can say for the radial data at this time is that the modulus is near 8.96 $x 10^{9} \mathrm{~Pa}\left(1.3 \times 10^{6} \mathrm{psi}\right)$. This is enough, however, to demonstrate that the coil modulus is practically the same in all directions, even in the radial direction where the cable strands are compressed on edge, if the coil is constrained on all sides. If not constrained, the cable would not be stable to such an edgewise application of stress.

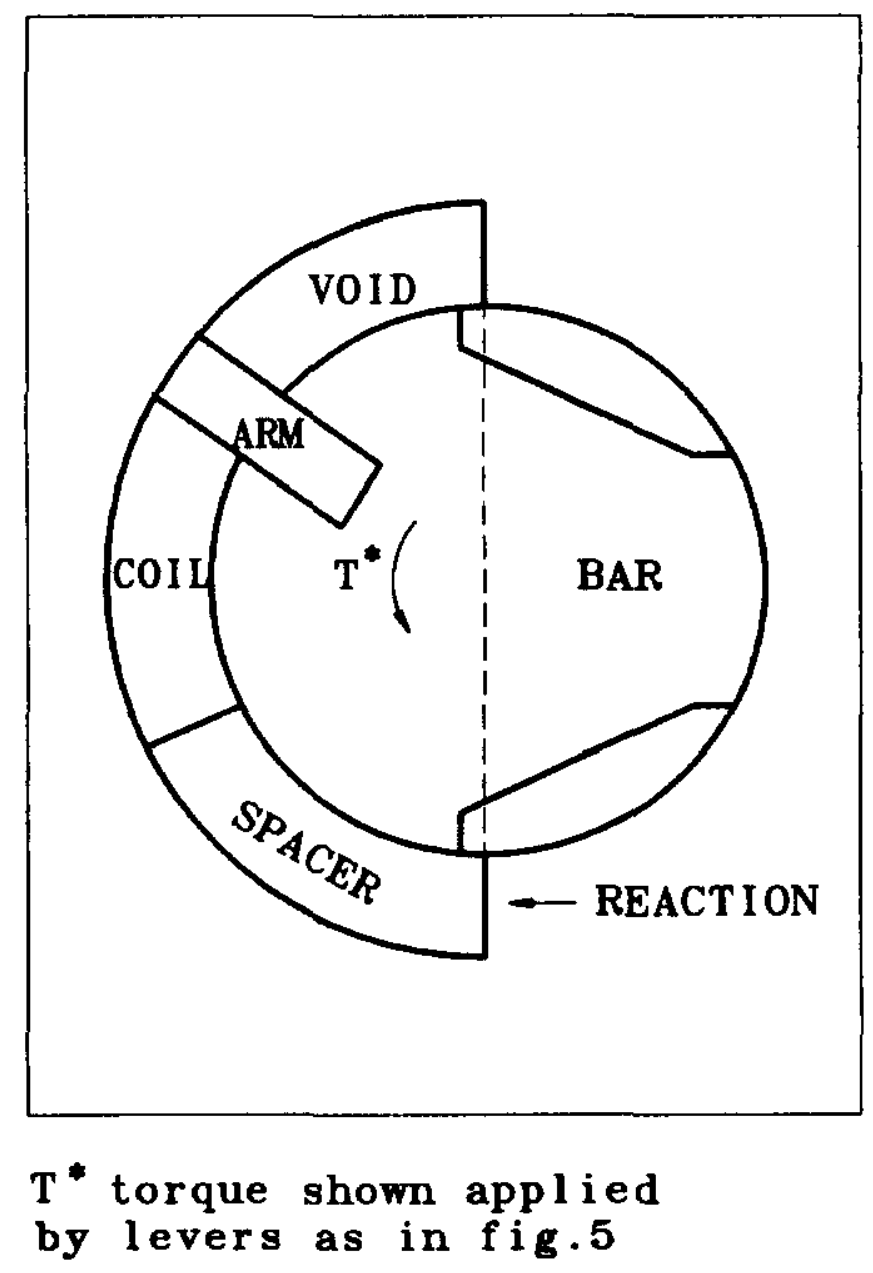

Figure 4. Azimuthal Modulus Fixture 


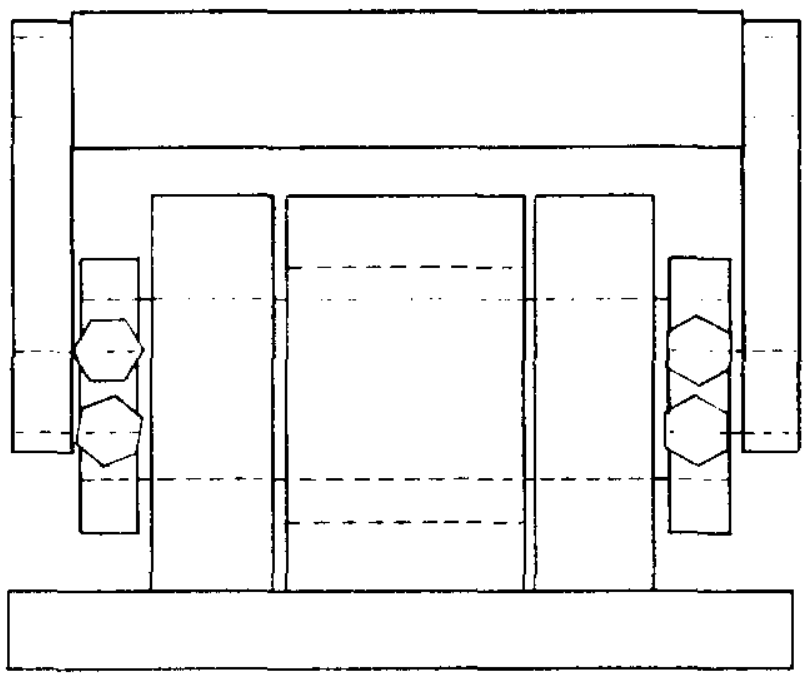

FRONT VIEW

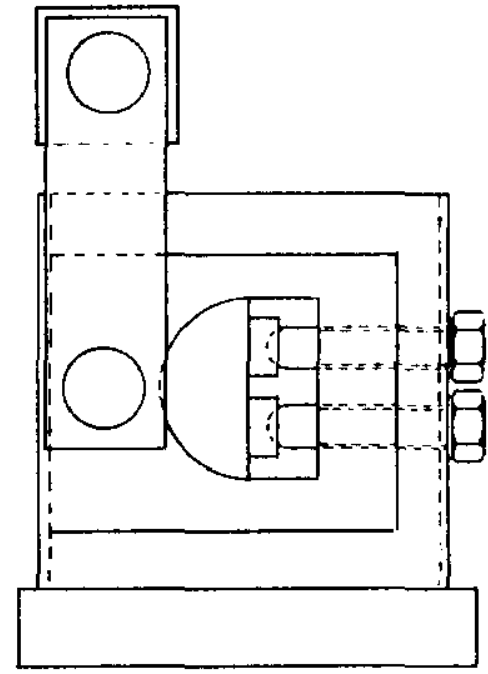

SIDE VIEW

Figure 5. Azimuthal Modulus Fixture, Lever Arrangement

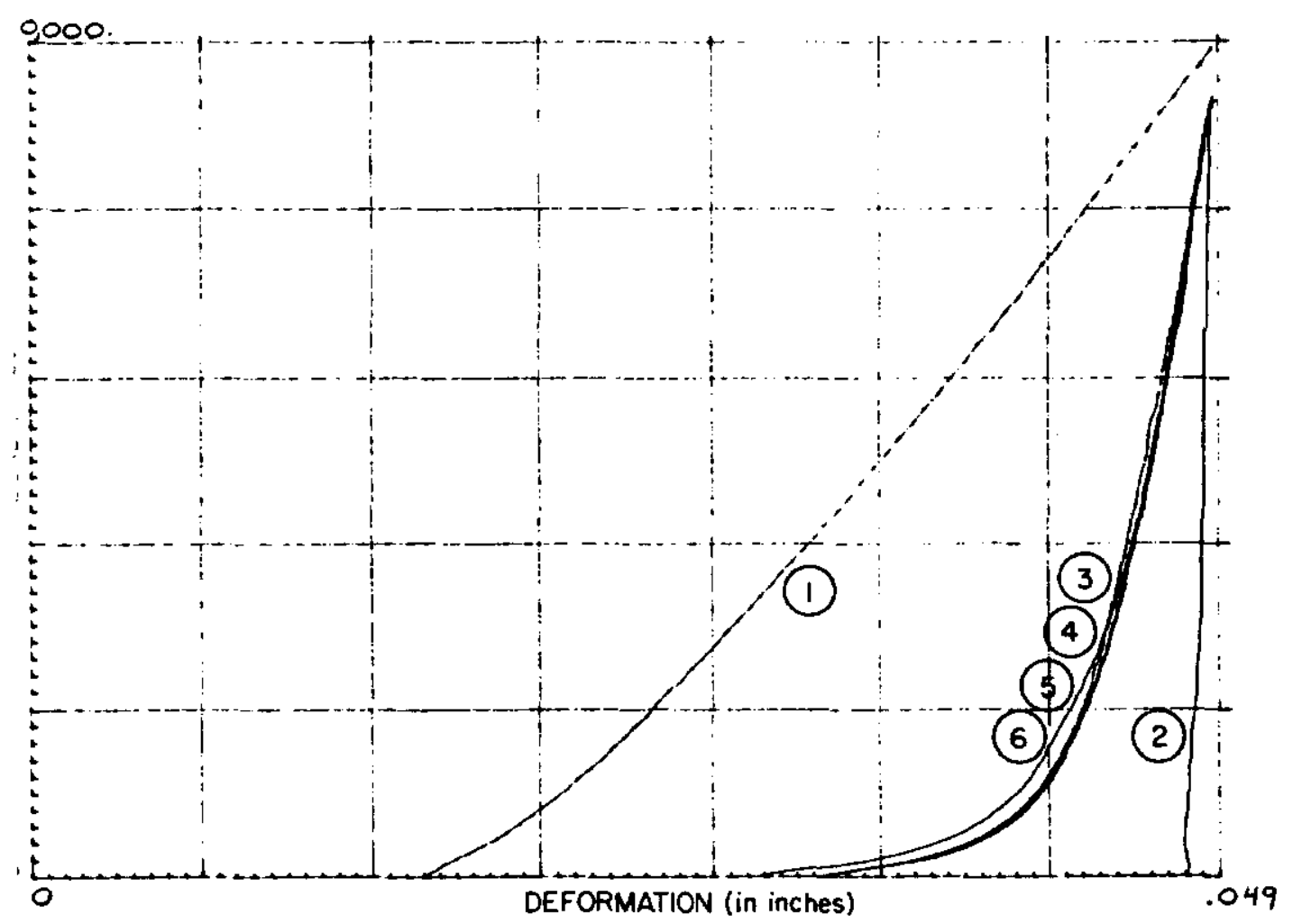

Figure 6. Azimuthal Data Normalized to $10,000 \mathrm{lbs}$. 

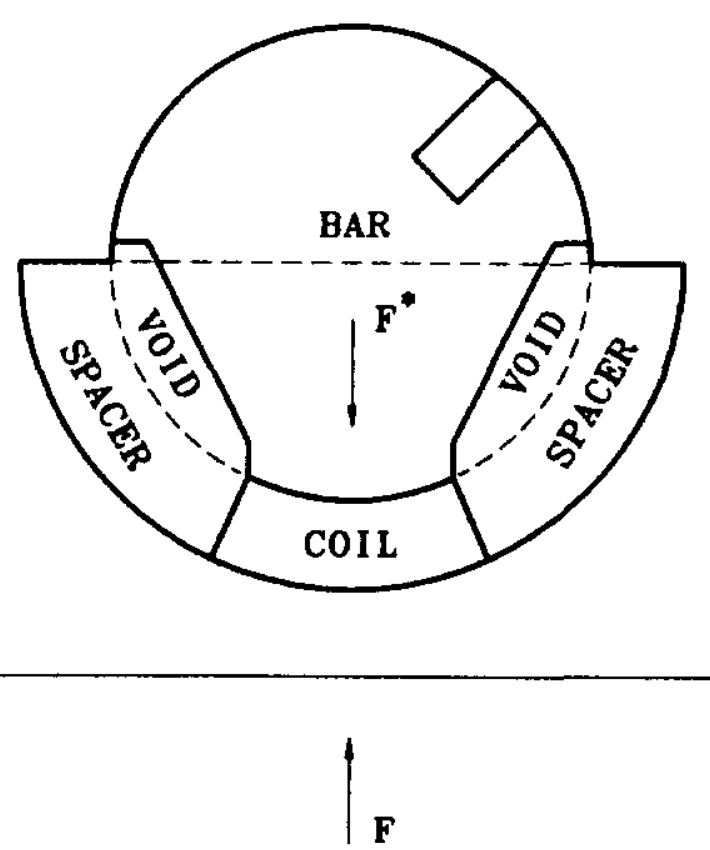

$F$ force applied through end blocks and bar.

Figure 7. Radial Modulus Fixture to 10,000 lbs.

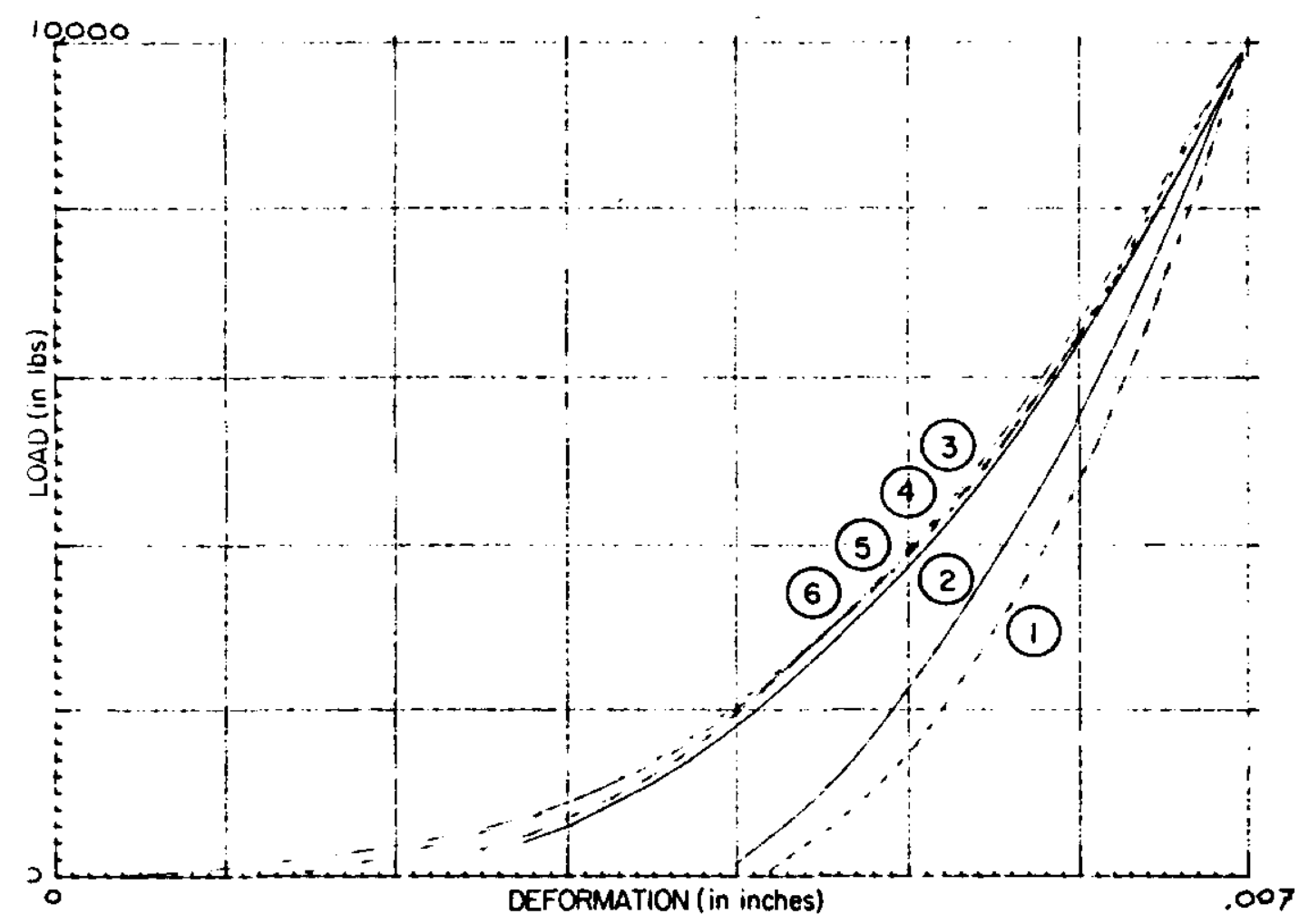

Figure 8. Radial data normalized to $10,000 \mathrm{lbs}$. 
A very precise azimuthal modulus of SSC $40 \mathrm{~mm}$ dipole outer coil has been measured at $1.43 \times 10^{10} \mathrm{~Pa}\left(2.08 \times 10^{6} \mathrm{psi}\right)$. Excellent agreement with an ANSYS model of the test fixture suggests that the uncertainties and corrections associated with this measurement are well understood.

A second set of measurements, in a different fixture, has allowed the measurement of the radial and azimuthal components of the elastic modulus of the same coils. In the azimuthal direction, a value of $8.48 \times 10^{9} \mathrm{~Pa}\left(1.23 \times 10^{6} \mathrm{psi}\right)$ was obtained, while in the radial direction the modulus varied as a weak function of load, from $8.96 \times 10^{9} \mathrm{~Pa}\left(1.3 \times 10^{6} \mathrm{psi}\right)$ at $4535 \mathrm{~kg}$ to $1.12 \times 10^{10} \mathrm{~Pa}\left(1.63 \times 10^{6} \mathrm{psi}\right)$ at $13603 \mathrm{~kg}$. Given the known nonlinearity of the load deflection curve of these coils, this change in calculated linear modulus is not surprising. While good agreement between the measured and actual aluminum block modulus in the azimuthal direction was obtained, poorer agreement was achieved in the radial direction. However, the data do suggest that these components of the coil modulus are not substantially different. The porosity of the coil may allow for the Poisson expansion of the cable, as if it were unconstrained.

The cause of the discrepancies between data taken in fixture \#1 and fixture \#2 is uncertain, although the complexity of fixture \#2 and the slightly lower load applied to the coil while in the fixture certainly contribute. Experience with previous test fixtures has shown that the total number of pieces in a fixture contribute to the uncertainty of the measurement. Indeed, this was the reason for the precision machining of fixture \#1 from a single piece of material. Although the data has been corrected for the fixture compliance, exactly replicating the fixture assembly from one test to the next is impossible. The modulus of these sections as measured here has also been shown to be a function of the applied load, so the lower load used in the second experiment would result in a lower apparent modulus.

The primary concern with the data is the limited number of samples which were available. This leaves the variability of properties from coil to coil unaddressed. A major factor in such variability is original strand diameter and consequently the amount of compression of the strands in the turkshead die during the cable manufacturing.

\section{REFERENCES}

1. Carson, J.A. and F.W. Markley, "Mechanical Properties of Superconducting Coils," IEEE Transactions on Magnetics, March, 1985, Volume MAG-21, \#2. A publication of the IEEE Magnetic Society, 345 East 47th Street, New York.

2. Markley, F.W. and J.S. Kerby, "Investigation of the Mechanical Properties of Superconducting Coils," Supercollider 2. Vol. 2, Plenum Press, New York, 1990, pp. 753 - 763. 